\title{
NOG IETS OMTRENT SURINAAMSCHE PLANTAGE-LEENINGEN
}

DOOR

C. K. KESLER

In een artikel „West-Indische Plantageleeningen” in de „Bijdragen en Mededeelingen” van het Historisch Genootschap vermeldt Dr. W. W. van der Meulen, dat er meer dan honderd van zulke leeningen bekend zijn en, dat er wellicht meer gesloten zijn en voegt hierbij, dat onder de papieren van verscheidene families daaromtrent nog wel meer zal te vinden zijn. Dat dit inderdaad het geval is, blijkt uit de hierbij gevoegde reproductie ${ }^{1}$ ) van een obligatie van zulk een leening uit het jaar 1765. De Heer Mr. Dr. P. H. W. G. van den Helm, Oud-GouvernementsSecretaris van Suriname, trof deze onder zijn familie-documenten aan en was zoo welwillend, haar voor de „WestIndische Gids" af te staan.

De negotiatie, waarop dit stuk betrekking heeft, dateert van 1 Mei 1765 en behoort dus tot de oudste groep. Zooals bekend is, kwam de eerste leening ten behoeve van Surinaamsche plantages in Mei 1753 tot stand door de bemoeiingen van den Amsterdamschen bankier en burgemeester W. G. Deutz, ten bedrage van $f 1.000 .000$. Later werden er wel negotiaties gesloten tot nog hoogere bedragen, enkele zelfs van meer dan $f 2.000 .000$. Die, waarop deze obligatie betrekking heeft, werd vastgesteld op een bedrag van honderd à honderdvijftig duizend gulden, dus belangrijk minder. Of dit kapitaal geheel volteekend is en of er ook obligaties tot een minder bedrag dan $f 1000$ zijn uitgegeven, heb ik niet kunnen opsporen; het komt mij

1) Alleen de derde bladzijde gereproduceerd. En twee coupons. 
voor, dat het eerste niet onmiddellijk het geval geweest is en daar het gestorte bedrag op het stuk met de pen is ingevuld, zal dit wel niet tot $f 1000$ alleen beperkt geweest zijn. Op de coupons staat echter dit bedrag wel gedrukt.

De „Conditiën en Voorwaardens”, waarop het kapitaal door verschillende particulieren verstrekt werd, waren ongeveer gelijk aan die van de meeste negotiaties uit de $18 \mathrm{e}$ eeuw.

Er zou geld worden verschaft, als le hypotheek opplantages door tusschenkomst van het Hof van Politie, en wel tot een bedrag, dat niet hooger mocht zijn, dan de helft van de getaxeerde waarde, tegen $6 \%$ 's-jaars en voor den tijd van 20 jaar. De eerste tien jaar hadden de geldnemers alleen rente te betalen, daarna moest elk jaar $10 \%$ van het voorgeschoten kapitaal afgelost worden.

De producten der verhypothekeerde plantages moesten uitsluitend geconsigneerd worden aan den Directeur der negotiatie, Nicolaas Brant, te Amsterdam; deze had te zorgen voor assurantie en voor den verkoop. Na aftrek van verschenen interest van het verschafte kapitaal, provisie en onkosten, was het netto provenu ter beschikking van den betrokken plantage-eigenaar. Ingeval deze van het bepaalde, omtrent consignatie van zijn product, afweek, was het geheele bedrag van de hypotheek met de verschenen interest onmiddellijk opvorderbaar.

Ingeval een plantage reeds met hypotheek bezwaard was, zou deze eerst moeten worden afgelost uit de verstrekte gelden.

Om de twee of drie jaar zou de plantage op kosten van den geldnemer opnieuw getaxeerd worden door één of twee, door de geldschieters, gemachtigden. Deze laatsten hadden tevens toe te zien, dat de bepaling omtrent de consignatie niet overtreden werd. De kosten van deze hertaxatie en van de verdere bemoeiingen der gemachtigden mochten niet meer dan $\frac{1}{2} \%$ van het bedrag der hypotheek bedragen.

De acte van oprichting der negotiatie werd gepasseerd ten kantore van den Amsterdamschen notaris P. de Wilde. Op het Gemeente-Archief, waar de minuten der acten 
van dezen notaris berusten. trof ik de oorspronkelijke acte van oprichting niet aan, wel andere, die op deze negotiatie betrekking hebben. Op 31 December 1771, b.v. compareerden voor den genoemden notaris , de Heer Nicolaas Brant, in zijn privé en als Directeur van een negotiatie ten Lasten van Planters in de Colonie Surinamen, opgericht primo May 1765 ten eenre, en de Heer Cornelis Buys van Keulen, ten anderen zijde". De laatste werd bij deze acte, door Nicolaas Brant, ,vermits deszelfs swakke Lighaamsgestalte,” gemachtigd, om als compagnon ,ter algemeenen nutte en welslagen van voorschreevene zijne negotiatie" op te treden, welke overeenkomst ,door een groot gedeelte der Intressanten, Geldschieters in deze negotiatie was geapprobeerd."

Blijkbaar gingen de zaken van deze negotiatie, evenals die van andere trouwens, niet naar wensch. Herhaaldelijk ontmoet men in het notarieel archief protesten van non-acceptatie of non-betaling van in Suriname afgegeven wissels, vaak belangrijke bedragen betreffende. Zoo vond ik op 17 Augustus 1770 een protest van wissels van Salomon Lijnslager in Suriname op Jan van de Poll Harmsz., door den nemer, Louis Richard, geëndosseerd aan Nicolaas Brant, loopende over bedragen van $f 3650$, $f 3000, f 2500$ en $f 2100$. Jan van de Poll Harmsz. weigerde acceptatie dezer wissels volgens de protest-acte „omreden, dat hij met Trekker geene Particuliere Correspondentie had." Op dezelfde wijze weigerden Jan en Th. van Marselis acceptatie en betaling van een wissel van Mosseh Henriquez, door Saml. Uz. d'Avilar geëndosseerd aan N. Brant of order, „omdat den Trekker bij hun onbekend was". Dergelijke acten komen herhaaldelijk voor; trouwens, het is bekend, dat juist in dien tijd heel wat met wissels in Suriname geknoeid werd.

Bepaalde feiten, waardoor deze negotiatie, evenals vele andere een mislukking geworden is, heb ik niet kunnen vinden. Dat het kapitaal slechts geleidelijk gefourneerd werd, wordt waarschijnlijk, doordat in latere jaren, dan dat van de oprichting der negotiatie nog obligaties geregistreerdwerden. Zoo b.v.2 Mei 1771 en 26 Mei 1772, en wel: 
9 obligaties ten name van Mr. Jan Cornelis Rademacher,

1 obligatie ten name van Dirk de Bak,

2 obligaties in blanco,

1 obligatie ten name van Ferd. Baron de Geyen en Vrouwe Alida Agnes de Fays.

Blijkens een aanteekening op de hierbijgevoegde obligatie werd tot 1 Mei 1770 de interest geregeld betaald; toen werden nieuwe coupons verstrekt voor de volgende vier jaar, dus tot Mei 1774, die vermoedelijk ook betaald werden. Daarna gingen de zaken blijkbaar verkeerd. De coupon van 1775 is waarschijnlijk nog betaald, die van '76 slechts voor $\frac{1}{3}$ en daarna bleef rentebetaling geheel achterwege.

In 1843 werd door de bankiersfirma Jos. Mendes da Costa te Amsterdam een onderzoek ingesteld, hoe het met deze negotiatie stond. In een particulier briefje bericht deze daaromtrent: „Op genoemde Obligatiën is sedert dien tijd (het is niet na te gaan, hoe lang. K.) niets betaald geworden, zoodat dezelven, althans nu, volstrekt geene waarde hebben."

„Althans nu”, - d. i. 27 April 1843. De bankiers laten echter in het midden, of zij nog ooit iets waard zullen worden, want zij voegen erbij: „Ik zal zorg dragen, zoo er nog vroeg of laat daaromtrent jets mogt geannonceerd worden, UEd. daarvan te verwittigen." Zouden het altijd vergeelde familiepapieren, niet meer dan herinneringen aan Suriname's achteruitgang blijven? Of zal in de laatste binnen kort een gunstige keer komen? 


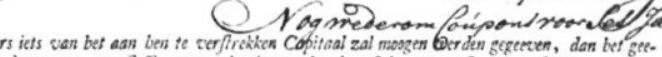

(6).

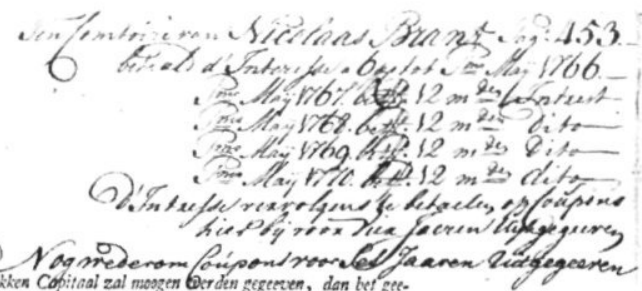

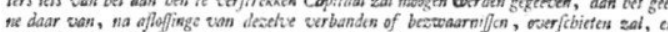

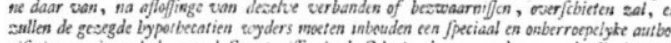

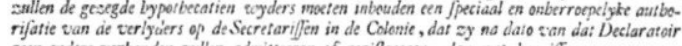
geen andere zerbanden sullen aduitteren of regiffrecen, dan met kenviffe en evoraterten van den Dirreletr, die datar inie nint ior

Eelfit der woarde ven de Plantagie toe. $x \mathrm{I}$.

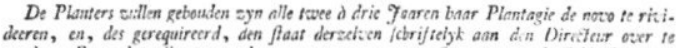

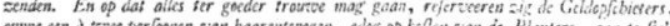

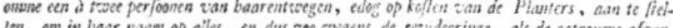

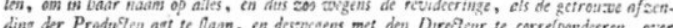

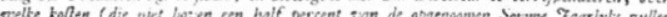

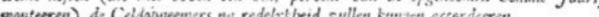

XII.

Den Direleter van dit Fonds in der tyd zal zyn grqualficuerd, en orraderrorplyk geatutherifeert, selfs met magt: van fubffitutic ad megotia ca as lites, om in cas de Planters in

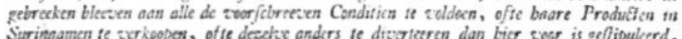
Surrinaman

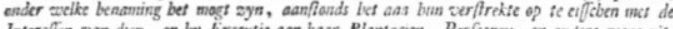

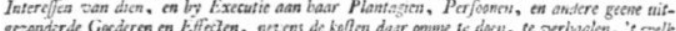

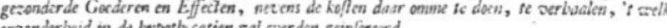
$\mathrm{X} I 1 \mathrm{I}$.

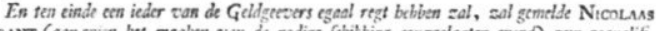

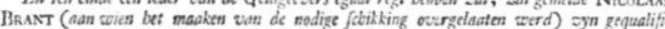

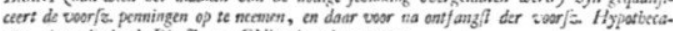
tiẹt, inqualiteit als Diredleur, Obligaticn nit te gavern.

$\mathrm{XIV}$.

Eindelyk, dat soo ras al bet in bereen gernelle af getoopxn ende de iypostecaticn albier

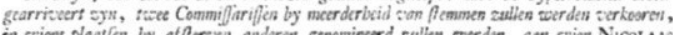

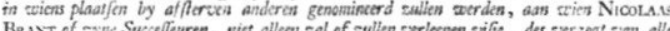

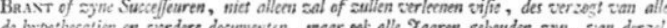

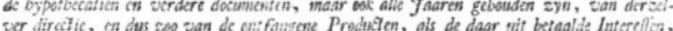

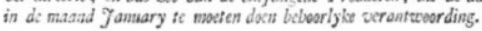

$N^{\circ} .1 .5 .3$ Ih ondergefchreeven Nicolus Brast, bekenne in de voorenflaande myne qua. SPCR. -. Litcit ontangen te hiebben uit handen van

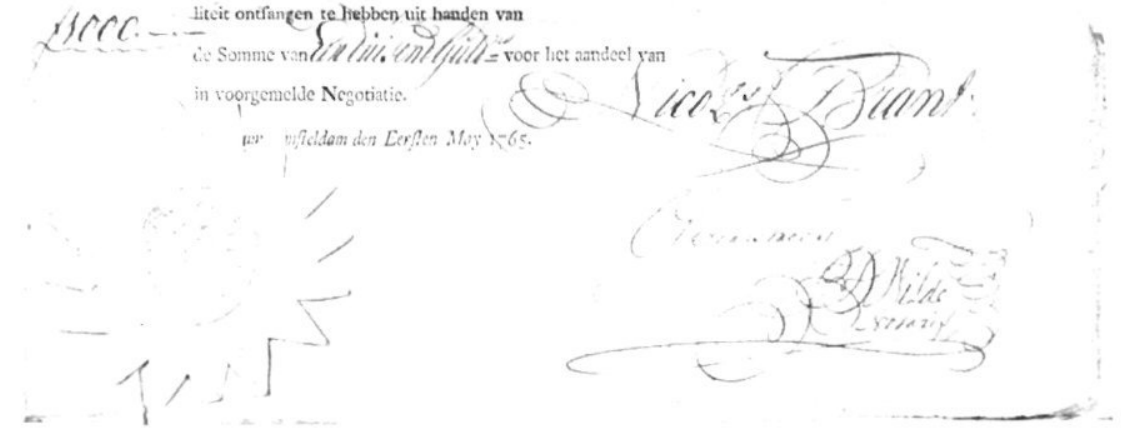




\section{Coupon $N^{\circ} \cdot 153$ - Betaalbaar Pmo. May i7 $\% 6$ met $f 60:-$ Holl. Ct.}

Op den Eerften May i7 Oal aan Toonder deezes, ten Comptoire van Nicolaas Brant, binnen

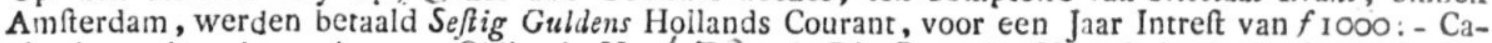
pitaal, aan hem ingevolge zyn Obligatie No.45.3, als Directeur der Negotiatie Ao. 7764 . opgeregt, ten behoeyen van Planters in de Colonje van Surinaine verftrekt.

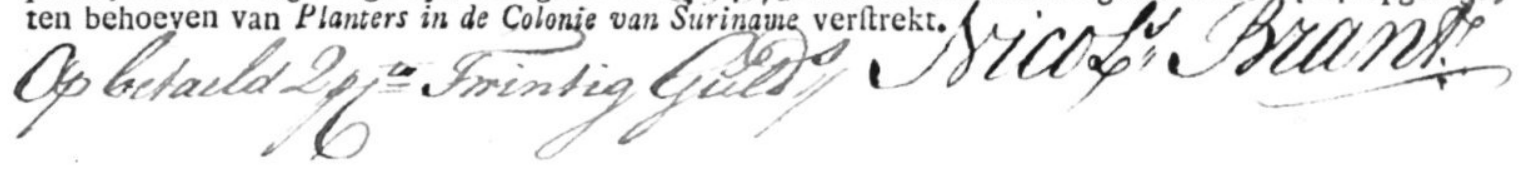

\section{Coupon $N^{\circ}$. 45.3 - Betaaibaar Pmo. May 17\%\%, met $f 60$ : - Holl. Ct.}

Op den Eerften May i 7 Y\% zal aan Toonder deezes, ten Comptoire van Nicolaas Brant, binnen Amfterdam, werden betaald Seftig Guldens Hollands Courant, voor een Jaar Intreft van f I000: - Capitaal, aan hem ingevolge zyn Obligatie No.45.3.- als Directeur der Negotiatie $\Lambda^{0}$. Iz64. opgerest ten behoeve van Planters in de Colonie van Suriname verftrekt.

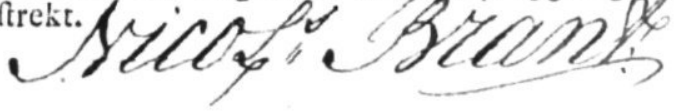

